\title{
$\mathrm{OA}$ 기기의 대기전력 측정을 통한 절전 평가 제안 \\ 김 만 건**최 돈 묵** \\ *한국전기안전공사. ${ }^{* *}$ 가천대학교 소방방재공학과
}

\section{The Recommendation on Power Saving through the Measuring of the Standby Power of OA Equipments}

\author{
Man-Geon Kim* ${ }^{*}$ Don-Mook Choi** \\ ${ }^{*}$ Korea Electrical Safety Corporation \\ ** Dept. of Fire Protection \& Disaster Eng., Gachon Univ.
}

\begin{abstract}
The purpose of this study was to assess power loss in the computer and office automation equipment and identified a way to save power consumptions through field measurement. In this study, the meaning of standby power was to consume power while waiting for the use of any electronic equipment. This standby consumption was about $11 \%$ of total power consumption even though we did not seriously realize it. Therefore, it was very important to measure accurate power consumption at the standby status of electronic equipment. In addition, it also helped to reduce potential risks of electricity associated disasters. This study proposed the way to reduce power losses through automatic turn off switches for power outlets and switches. Finally, this study can evaluate power consumption patterns that can reduce power consumptions and potential risks of power related disasters. This also can achieve the goals of sustainability that can reduce environmental impacts by lowering energy consumptions and greenhouse gas emissions.
\end{abstract}

Keywords : Standby Power, Standby Power Methods, Types of Standby Power Saving

\section{1. 서 론}

최근 전기에너지의 사용이 급증하면서 갑작스런 순 환정전 등과 같은 전력수급의 불균형 문제가 대두되고 있다. 순환정전과 같은 외부충격은 일상생활과 국가경 제 전체에 심각한 영향을 미치기 때문에, 가정과 사무 실 및 사업장에서의 전기설비나 전기기계기구 등에서 불필요하게 발생하는 전력손실을 줄이는 노력이 요구 된다. 이에 정부와 관련기관에서는 에너지를 절약하기 위한 아이디어 공모와 함께 절전을 적극적으로 실천하 기 위해 대기전력(standby power)차단 등 에너지 낭비 를 최소화하는 방향으로 정책을 수행하고 있다[1].
대기전력이란 전원을 사용하는 부하와 전원공급원을 연결하는 부분에서 실제 부하가 가동되지 않는 시점에 서 본래의 기능과 무관하게 전기에너지가 소모되는 것 을 의미한다. 하지만, 대기전력을 국제전기위원회(IEC), 국제에너지기구(IEA) 및 각 나라 별로 정의하고 있으나 국제적으로는 용어의 정의가 통일되지 않은 상태이다.

대기전력 절전에 관한 연구는 일본의 top runner 프 로그램과 스위스의 규제 프로그램, 미국의 에너지스타 (energy star) 프로그램 및 프랑스, 독일, 네덜란드, 스 웨덴 등 유럽 8개 국가에서 시행중인 GEA(Group for Efficient Appliances) 등급제 등을 통해 대기전력을 $1[\mathrm{~W}]$ 이하로 줄이는 정책을 시행하고 있는 추세이다[2].

\footnotetext{
† 이 연구는 2013년도 가천대학교 지원(GCU-2011-R181)에 의해 연구되었음.

† Corresponding Author: Prof, Don-Mook Choi, Gachon Univ., 1342 SeongnamDaero, Sujeon-Gu, Soengnam-Si, Gyeonggi-Do, Korea, 461-701. Tel : 031-750-5716, E-mail : fire@gachon.ac.kr Received October 3, 2012; Revision Received February 12, 2013; Accepted March 16, 2013.
} 
우리나라도 $1[\mathrm{~W}]$ 인 대기전력저감 기준을 2015년까지 $0.5[\mathrm{~W}]$ 로 강화하고, 건축물에 대한 대기전력 차단장치 의무설치 비율을 기존 $30 \%$ 에서 $50 \%$ 로 상향 조정토록 관련 부처와 협의·추진하고, 멀티탭과 콘센트 등 차단 장치 보급사업과 함께 연구도 병행하면서 추진하고 있 다. 그러나 국내에서는 여전히 가전기기 $(\mathrm{FA})$ 나 사무용 기기(OA; Office Automation) 등이 대기상태에서 소비 전력 자체가 적다는 이유 등으로 관리를 소홀히 하거 나 방치하고 있는 경우가 상당히 많은 편이다.

본 연구는 대기전력의 특성을 연구하여 사용하지 않 을 때나 대기상태에서 입력전원을 차단하거나 원천적 으로 대기전력을 현저하게 낮추는 방법 등을 제안하고 자 한다. 이러한 연구를 통해, 본 연구는 대기전력에 의한 전력손실을 대폭 줄임으로써 근원적으로 전기에 너지를 절전함과 동시에 전기화재를 예방하고 전기요 금을 줄이는 목적을 달성하고자 한다.

2. 본 론

\section{1 대기전력 발생과 정책}

2011년 우리나라에서 연간 4,200억 원이 대기전력으 로 새나가면서 대기전력을 전기 흡혈귀라고 부르기까 지 한다[3]. 개별 사무용기기의 대기전력은 비록 적다 하더라도 사무실이나 기업 및 국가차원으로 합산하면 매우 많은 전력이 무의미하게 소모되어 귀중한 자원으 로 만든 전기에너지를 낭비하고 있는 것이 현실이다.

<Table 1>과 <Table 2>에 우리나라의 대기전력의 단계적 목표와 대기전력 $1[\mathrm{~W}]$ 이하의 기준에 대해 나 타내었다. 이 표에서 확인할 수 있듯이 '04년 정부는 "대기전력 낭비를 막기 위해 2010년까지 모든 전자제 품의 대기전력을 $1[\mathrm{~W}]$ 이하로 할 수 있도록 대기전력 절약기술 개발을 지원하고 정부 우선 구매와 보급 촉 진 등 지원책을 아끼지 않을 것”이라고 강력한 대기전 력 절감의지를 공식적으로 선포한 후 적극적으로 추진 하고 있다[4].

$<$ Table 1> Annual Goals of "Standby Korea 2010"

\begin{tabular}{|c|c|c|c|c|}
\hline \multirow{2}{*}{ Division } & \multirow{2}{*}{$\begin{array}{c}2005 \\
\text { (Base year) }\end{array}$} & \multicolumn{3}{|c|}{ Goals } \\
\hline & & 2007 & 2010 & 2020 \\
\hline $\begin{array}{l}\text { 1. Standy power management items } \\
\text { (Standy power reduced programs) } \\
\text { (Energy efficiency grade marking system) }\end{array}$ & $\begin{array}{c}18 \text { item } \\
(18) \\
(0) \\
\end{array}$ & $\begin{array}{l}22 \text { item } \\
(20) \\
(2) \\
\end{array}$ & $\begin{array}{l}30 \text { item } \\
(24) \\
(6) \\
\end{array}$ & $\begin{array}{c}\begin{array}{c}30+1 \mathrm{Y} \text { item } \\
(30+1 \mathrm{Y}) \\
(6)\end{array} \\
\end{array}$ \\
\hline 2. Average standby power of commercially available equipment & - & $3.0[\mathrm{~W}]$ & $2.0[\mathrm{~W}]$ & $1.0[\mathrm{~W}]$ \\
\hline 3. Retention devices in the household, the average standby power & $3.66[\mathrm{~W}]$ & $3.3[\mathrm{~W}]$ & $2.5[\mathrm{~W}]$ & $2.0[\mathrm{~W}]$ \\
\hline 4. Standy power $1[\mathrm{~W}]$ device penetration rate & $22 \%$ & $30 \%$ & $40 \%$ & $80 \%$ \\
\hline 5. Annual standby power savings & - & - & $1,100 \mathrm{GWh}$ & $6,800 \mathrm{GWh}$ \\
\hline 6. Annual $\mathrm{CO}_{2}$ emissions reduction & - & - & 53,000Ton & 329,000 Ton \\
\hline
\end{tabular}

$<$ Table $2>$ Standy Power $\leq 1[\mathrm{~W}]$ Standards applicable status

\begin{tabular}{|c|c|c|}
\hline Division & Enforcement date & Target goods \\
\hline \multirow{5}{*}{$\begin{array}{l}\text { Energy efficiency grade marking } \\
\text { system }\end{array}$} & By the end of 2006 & $\begin{array}{l}\text { TV, Adapters, Mobile phone chargers, Copiers, Wired and } \\
\text { wireless phones, Automatic power-saving control devices }\end{array}$ \\
\hline & 07.1 .1 & Monitors, Printers, Scanners, Radio cassette \\
\hline & 07.7 .1 & Video, Audio, DVD players, Set-top boxes, Microwaves \\
\hline & 08.1 .1 & Modem, Bidets, Door phones \\
\hline & 09.1 .1 & Computers, Official replicators \\
\hline \multirow{6}{*}{$\begin{array}{l}\text { Energy consumption efficiency, } \\
\text { Class } 1 \text { standards }\end{array}$} & 07.1 .1 & Electric washing machines, Dishwashers \\
\hline & "08.1.1 & Electric rice cookers \\
\hline & 08.7.1 & Air cleaners \\
\hline & '09.1.1 & $\begin{array}{l}\text { Drum-type washing machines, Fans, Adapters and } \\
\text { Chargers }(\leq 0.5[\mathrm{~W}] \text { MEPS })\end{array}$ \\
\hline & ‘0.1.1 & Air conditioners \\
\hline & ‘11.1.1 & Dish dryers \\
\hline
\end{tabular}




\section{2 대기전력 정의}

대기전력과 관련된 국제기구나 $\mathrm{OECD}$ 주요국들은 대 기전력을 다음과 같이 정의하고 있다. 국제에너지기구 에서는 "대기전력은 최소한 기기가 어떤 기능도 수행 하지 않을 동안 소모되는 전력을 포함한다[2]. 많은 제 품에서 대기전력은 최소한 한 가지의 기능을 수행하는 동안에 소모하는 최소전력"으로 정의하고 있으며, 국제 전기기술위원회는 "대기모드(Standby)란, 기기가 주전 원과 연결되어 있고 제조자가 정한 방법에 따라 사용 되는 임의의 시간 동안에 나타나는 최저 전력모드로 사용자에 의해 제어될 수 없는 모드이다." 여기서 대기 모드란 대체로 비동작 모드로서 기기의 주 기능을 인 위적으로 사용하는 경우와 구별된다. 대기전력은 국제 전기위원회, 국제에너지기구 및 각 나라 별로 각각 정 의하고 있으며, 국제적으로 통일된 정의는 없다. 전기 에너지를 $\mathrm{OA}$ 기기 등이 외부의 전원과 연결된 상태에 서 해당기기의 주 기능을 수행하지 않거나 또는 외부 로부터의 켜짐 신호를 기다리는 상태에서 소비되는 전 력을 대기전력이라 한다[2].

본 연구에서는 대기전력의 정의를 아래와 같이 제안
하고 사무용기기의 대기전력실측조사를 수행하였다. 대 기전력이란 “전원콘센트에 $\mathrm{OA}$ 기기 등의 플러그가 꼽 혀 있거나 전원에 연결되어 있는 상태로 실제 사용하 지 않는 시간대에 소비되는 전력으로 리모컨 신호대기, 타이머 또는 컴퓨터의 모니터 표시 등과 같이 기기 본 래의 기능과 무관하게 전기가 낭비되고 있는 전력"을 말한다.

\section{3 대기전력 종류와 발생패턴}

대기전력은 실제로 사용하지 않는 시간대에 소비되 는 전력으로서 기기가 작동하기 위해 필요한 전력을 공급하는 전원장치의 저항과 같은 수동 부품과 금속 산화막 반도체 전계효과 트랜지스터(MOS-FET)나 절 연 게이트 양극성 트랜지스터(IGBT) 등의 파워스위치 에서의 손실 및 전원장치를 제어하는 집적회로(IC)에서 대기전력을 발생한다. 대기전력 발생패턴은 <Table 3> 과 같은 무부하모드(No Load Mode), 오프모드(Off Mode), 수동대기모드(Passive Standby Mode), 능동대 기모드(Active Standby Mode), 슬립모드(Sleep Mode) 에서 일어난다[2].

$<$ Table 3> Standby power generation pattern

\begin{tabular}{|c|c|c|c|}
\hline Division & Concept & Power status & Target Goods \\
\hline No Load Mode & $\begin{array}{c}\text { The power consumed in the state } \\
\text { plugged. }\end{array}$ & Plug in & $\begin{array}{c}\text { Adapters and Chargers, } \\
\text { Electric rice cookers } \\
\text { (Standby Power } 1 \mathrm{~W} \text { policy Target) }\end{array}$ \\
\hline Off mode & $\begin{array}{l}\text { The power consumption when power } \\
\text { is turned off using the power button. } \\
0 \sim 3[\mathrm{~W}] \text { consumption }\end{array}$ & Switched off & $\begin{array}{c}\text { Video, Audio, DVD players, } \\
\text { Microwaves, PC, Monitors, Printers, } \\
\text { Copiers, TV }\end{array}$ \\
\hline $\begin{array}{l}\text { Passive Standy } \\
\text { Mode }\end{array}$ & $\begin{array}{l}\text { The power consumption when power } \\
\text { is turned off by remote control. } \\
\text { Domestic standby power reduction } \\
\text { program(Energy saving mark) } 3 \mathrm{~W} \\
\text { level }\end{array}$ & Switched off & $\begin{array}{l}\text { TV, Videos, Audios, DVD players, } \\
\text { Air Conditioners, Air cleaners }\end{array}$ \\
\hline Active Standy Mode & $\begin{array}{l}\text { Did not turn off when the power is } \\
\text { off, the actual state for } \\
\text { communication with external devices } \\
\text { on a networked digital devices } \\
\text { ranging from } 20 \sim 40[\mathrm{~W}] \text { standby } \\
\text { power consumption. }\end{array}$ & Switched off & $\begin{array}{l}\text { Set-top boxes, } \\
\text { Home networks }\end{array}$ \\
\hline Sleep Mode & $\begin{array}{l}\text { The power consumption in the } \\
\text { standby state, the behavior of the } \\
\text { devices do not use }\end{array}$ & On and standby & $\begin{array}{l}\text { PC, Monitors, Printers, } \\
\text { Facsimile, Copiers, } \\
\text { Scanners, Official replicators }\end{array}$ \\
\hline
\end{tabular}




\section{4 대기전력 실측}

\subsection{1 대기전력 측정 계측기}

대기전력측정은 기본계측기로 에이디파워(주)사 제품 인 와트맨(HPM-100A, NO: 062022), Hioki사 제품인 클램프메타(NO 3285-20), AMETEK사 제품인 전력 분 석계(NO APEX-6000)를 사용하였으며, 각 측정모드의 순시치 $(\mathrm{W})$ 를 계측하였다.

각 측정기기는 검 - 교정전문기관으로부터 검 - 교정 을 받아 신뢰도를 확보하였으며, 측정상의 오차를 줄이 고 신뢰도를 높이기 위해서 다음과 같은 측정방법을 채택하였다[1].

\subsection{2 대기전력 측정방법}

그림 1 과 같은 대기전력 측정장치를 사용하여 다음 과 같은 방법으로 측정하였다.

(1) 측정하기 전에 계측기를 상온상태에서 10 분 이상 책상위에 놓아둠으로써 예열하여 비정상적인 동작을 방지하였다.

(2) 전원콘센트에 대기전력 측정 장비의 전원코드를 연결하고, 측정대상기기의 전원코드플러그를 대기전력 측정 장비 측정단자함에 접속하였다.

(3) 접속한 상태에서 1 분 이상 안정화시켜 접속돌입전 류 등에 의한 영향을 제거하였다.

(4) 사무실에서 실제로 측정할 경우 $220 \mathrm{~V}$ 의 정격전 압으로부터 표준전압 및 허용오차 범위 내에서 측정할 수 있도록 정격전압 $220 \pm 13 \mathrm{~V}$ 를 벗어날 경우와 표준주 파수 및 허용오차 $60 \pm 0.2 \mathrm{~Hz}$ 의 오차범위를 미리 조사 한 결과 측정전압은 $227.7 \pm 0.2 \mathrm{~V}$ 이내와 주파수는 $60 \mathrm{~Hz}$ 로 오차범위에서 안정된 상태였다. 그리고 모든 측정조 건에서 공급전압은 227.5 227.9 V 범위를 넘지 않았다.

(5) 대기전력 측정기 와트맨(HPM-100A) Hand- Held 타입 전력계는 $9 \mathrm{~mW} \sim 3.75 \mathrm{~kW}$ 이하인 가전 및 사무기기 등의 소비전력과 대기전력을 Plug \& Play 방식으로 측 정용이며 측정된 전력량을 전기요금, 이산화탄소 배출 량으로 쉽게 환산이 가능하였고 기본 오차 $\pm 0.4 \%$ 이 내였다.

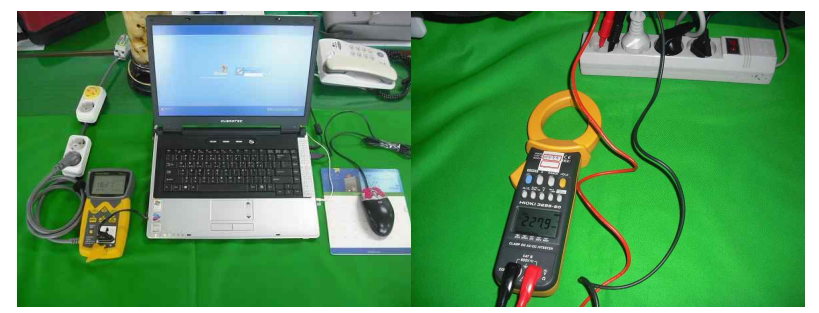

[Fig. 1] Standby power Meter

\subsection{3 대기전력 실측 결과}

대기전력 실측조사는 일반사무실(경기도 평택시 비전 동 834 사무실)에 있는 $\mathrm{OA}$ 기기를 표본 대상으로 하여 사무실 내 $\mathrm{OA}$ 기기의 대기전력을 측정하고 평균대기전 력 발생시간을 조사하여 대기전력을 산출하였으며, 측 정대상기기는 사무실에서 $220 \mathrm{~V}$ 전원에 접속하는 모든 $\mathrm{OA}$ 기기를 대상으로 하였다. 단, 냉장고나 팩스, 방범장 비와 같이 상시전원을 투입하여야하는 기기 및 사용빈 도가 낮은 비디오카메라, 전기다리미, 헤어드라이어 등 은 조사대상에서 제외하였다.

<Table 5>에 $\mathrm{OA}$ 기기별 소비전력과 대기전력 실측 조사에 대하여 나타내었다. 표에 나타내었듯이 각 기기 별 평균전력에서 대기전력이 차지하는 비율은 약 $1 \%$ 에서 $7.8 \%$ 까지 다양하였다. 이를 합산한 결과는 그림 2에 나타냈다[4].

[Fig. 2]에서 한 사무실에 존재하는 컴퓨터의 수량과 이때 소모되는 대기전력을 파악한 후 전체를 합산한 결과 약 46.8[W]인 것으로 확인되었다.

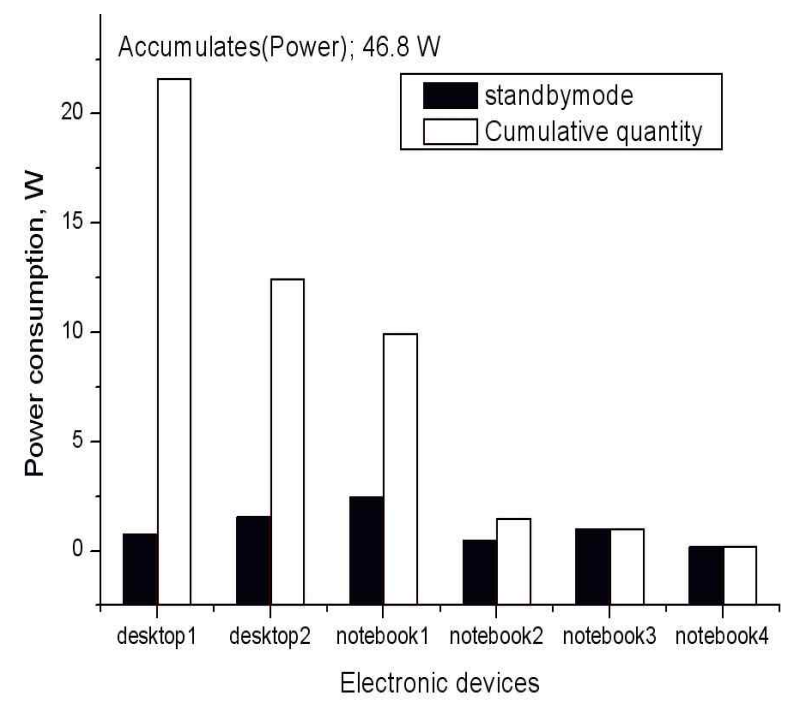

[Fig. 2] Comparison of cumulative power consumption standby power

이는 통상적으로 노트북 2대를 쓰는 소비전력보다 많은 전력이 낭비되고 있음을 확인할 수 있다. 일반사 무실에서 $\mathrm{OA}$ 기기를 이용하지 않더라도 대기전력으로 인하여 노트북 2 대 이상 사용하는 전력을 소모하는 것 으로 확인되었으며, 사무기기에서 모니터, 프린터, 스피 커 등에 의해 소비되는 전력과 대기전력량을 비교한 결과 제품에 따라 약 $4.6 \%$ 에서 $7.5 \%$ 에 이르는 전력 이 낭비되고 있는 것으로 나타났다. 
$<$ Table $4>$ Power consumption of computer peripherals and Atmospheric Electricity Comparison

\begin{tabular}{|c|c|c|c|}
\hline Division & Monitor & Printer & Speaker \\
\hline $\begin{array}{c}\text { Consumption electricity } \\
\text { (W) }\end{array}$ & 100 & 430 & 20 \\
\hline $\begin{array}{c}\text { Atmospheric } \\
\text { electricity(W) }\end{array}$ & 5 & 20 & 1.5 \\
\hline
\end{tabular}

$<$ Table 5> Survey at the actual OA equipment, power consumption and standby power

\begin{tabular}{|c|c|c|c|c|c|}
\hline Division & $\begin{array}{l}\text { Power } \\
\text { Supply }\end{array}$ & $\begin{array}{c}\text { Average } \\
\text { power }\end{array}$ & $\begin{array}{l}\text { Sleep } \\
\text { mode }\end{array}$ & $\begin{array}{l}\text { Standy } \\
\text { Power }\end{array}$ & ea. \\
\hline $\begin{array}{l}\text { Desktop } 1 \\
\text { 220V, 3A }\end{array}$ & $86 \mathrm{~W}$ & $82 \mathrm{~W}$ & $1.50 \mathrm{~W}$ & $0.81 \mathrm{~W}$ & 27 \\
\hline $\begin{array}{l}\text { Desktop } 2 \\
220 \mathrm{~V} 4 \mathrm{~A}\end{array}$ & $76 \mathrm{~W}$ & $69.49 \mathrm{~W}$ & $2.05 \mathrm{~W}$ & $1.56 \mathrm{~W}$ & 8 \\
\hline $\begin{array}{c}\text { Notebook } 1 \\
100^{\sim} 240 \mathrm{~V}, 2.4 \mathrm{~A}\end{array}$ & $34.7 \mathrm{~W}$ & $31.94 \mathrm{~W}$ & $2.00 \mathrm{~W}$ & $2.49 \mathrm{~W}$ & 4 \\
\hline $\begin{array}{c}\text { Notebook } \\
100^{\sim} 240 \mathrm{~V}, 1.5 \mathrm{~A}\end{array}$ & $16.05 \mathrm{~W}$ & $13.29 \mathrm{~W}$ & $0.901 \mathrm{~W}$ & $0.49 \mathrm{~W}$ & 3 \\
\hline $\begin{array}{c}\text { Notebook } 3 \\
100^{\sim} 240 \mathrm{~V}, 1.7 \mathrm{~A}\end{array}$ & $18.07 \mathrm{~W}$ & $16.62 \mathrm{~W}$ & $4.641 \mathrm{~W}$ & $1.04 \mathrm{~W}$ & 1 \\
\hline $\begin{array}{c}\text { Notebook } 4 \\
100^{\sim} 240 \mathrm{~V}, 1.5 \mathrm{~A}\end{array}$ & $17.79 \mathrm{~W}$ & $13.42 \mathrm{~W}$ & $0.787 \mathrm{~W}$ & $0.10 \mathrm{~W}$ & 1 \\
\hline $\begin{array}{c}\text { Laser Printer } \\
220^{\sim} 240 \mathrm{~V}, 4.1 \mathrm{~A}\end{array}$ & $825 \mathrm{~W}$ & & & $7.12 \mathrm{~W}$ & 4 \\
\hline $\begin{array}{c}\text { Inkjet Printer } 1 \\
100^{\sim} 240 \mathrm{~V}, 1 \mathrm{~A}\end{array}$ & $85 \mathrm{~W}$ & & & $4.05 \mathrm{~W}$ & 1 \\
\hline $\begin{array}{l}\text { Inkjet Printer } 2 \\
100^{\sim} 240 \mathrm{~V} 1.8 \mathrm{~A}\end{array}$ & $22.8 \mathrm{~W}$ & & & $5.4 \mathrm{~W}$ & 4 \\
\hline $\begin{array}{c}\text { Copier } \\
220^{\sim} 240 \mathrm{~V} 4.2 \mathrm{~A}\end{array}$ & $924 \mathrm{~W}$ & & $7.998 \mathrm{~W}$ & $23.05 \mathrm{~W}$ & 1 \\
\hline $\begin{array}{c}\text { Scanner } \\
100^{2} 240 \mathrm{~V}, 1 \mathrm{~A}\end{array}$ & $440 \mathrm{~W}$ & & & $10.61 \mathrm{~W}$ & 1 \\
\hline $\begin{array}{c}\text { Projector } \\
100^{\sim} 240 \mathrm{~V}, 3.6 \mathrm{~A}\end{array}$ & $323.3 \mathrm{~W}$ & & & $16.40 \mathrm{~W}$ & 1 \\
\hline $\begin{array}{c}\text { Facsimile } \\
220 \mathrm{~V}, 2.1 \mathrm{~A}\end{array}$ & $11.03 \mathrm{~W}$ & & & $5.15 \mathrm{~W}$ & 1 \\
\hline $\begin{array}{l}\text { Coffee vending } \\
\text { machine } \\
220 \mathrm{~V}, 3.71 \mathrm{~A}\end{array}$ & $48.98 \mathrm{~W}$ & & & $25.45 \mathrm{~W}$ & 1 \\
\hline $\begin{array}{c}\text { Water purifier, } \\
220 \mathrm{~V}\end{array}$ & $\begin{array}{l}690 \mathrm{~W} \\
550 \mathrm{~W}\end{array}$ & & & $4.23 \mathrm{~W}$ & 1 \\
\hline $\begin{array}{c}\text { Mobile phone } \\
\text { charger } \\
100^{\sim} 240 \mathrm{~V}, 200 \mathrm{~mA}\end{array}$ & $6.408 \mathrm{~W}$ & & & $0.64 \mathrm{~W}$ & 1 \\
\hline $\begin{array}{l}\text { Fan heater } \\
220 \mathrm{~V}, 5.8 \mathrm{~A}\end{array}$ & $1340 \mathrm{~W}$ & & & $4.15 \mathrm{~W}$ & 1 \\
\hline $\begin{array}{c}\text { TV(CRT) } \\
110^{\sim} 220 \mathrm{~V}, 0.36 \mathrm{~A}\end{array}$ & $71.32 \mathrm{~W}$ & & & $8.78 \mathrm{~W}$ & 1 \\
\hline
\end{tabular}

대기전력측정기로 $\mathrm{OA}$ 기기 종류별로 전력사용량과 대기전력 실측조사를 한 결과 사무용기기들의 평균 대 기전력은 $3.66[\mathrm{~W}]$ 이상이었다.

$\mathrm{OA}$ 기기 등에서 대기전력이 발생하는 원인은 전원에 서 IC(Integrated Circuit)로 들어오면서 거쳐야하는 기 동전압과 $\mathrm{IC}$ 가 동작할 때의 전류 등에 의해 일어나며, 컴퓨터의 경우 데스크 탑 컴퓨터에 USB 등 부하의 크 기와 종류에 따라 소비전력량에 차이가 나타나고, 노트 북의 경우 배터리 장착여부에 따른 소비전력 변화가
크게 나타났다. 따라서 사무실 등에서 상용전원에 연결 하여 사용할 경우는 절전과 배터리 수명측면에서는 배 터리 분리 후 사용하는 것이 경제적이다. 그리고 사무 실과 가정 등에서 피쳐폰이나 스마트폰을 충전하기 위 해 직류전원장치를 콘센트에 꽂아두고 방치할 경우의 대기전력 소비실태조사 및 분석한 결과, $\mathrm{LED}$ 램프 있는 멀티 탭 스위치를 $\mathrm{ON}$ 하면 $\mathrm{LED}$ 램프의 소비전력은 약 $0.23 \sim 0.45[\mathrm{~W}]$ 이며, 하루 동안 $\mathrm{ON}$ 상태로 방치할 경우 에는 낭비되는 대기전력은 $10.8[\mathrm{Wh}]$ 의 전력이 소모되었다.

피쳐폰 충전기용 직류전원장치가 연결된 상태에서 $\mathrm{LED}$ 램프 있는 스위치 2개를 $\mathrm{ON}$ 하면 소비전력은 약 $1.17[\mathrm{~W}]$ 로, 24 시간 방치할 경우에는 소비전력 즉 대기 전력으로만 $28[\mathrm{Wh}]$ 의 전력이 낭비된다. 한 달 동안 방 치하면 $840[\mathrm{Wh}]$ 이고 3 인 가족이 사용하면 $2.52[\mathrm{kWh}]$ 가 된다.

피쳐폰 충전기용 직류전원장치가 연결된 상태에서 충전하고 있을 때는 소비전력은 약 $5.5[\mathrm{~W}]$ 가 되며 약 1 2시간 정도면 충전이 완료되기 때문에 충전이 완료 되면 전원스위치를 꺼야 $(\mathrm{OFF})$ 대기전력을 차단하여 전 기를 절약할 수 있다.

스마트폰 또한 충전기용 직류전원장치가 연결된 상 태에서 충전하고 있을 때는 소비전력은 약 $3.79[\mathrm{~W}]$ 가 되며 약 1 2시간 정도면 충전이 완료된다. 충전이 완 료되면 전원스위치를 꺼야 대기전력을 차단할 수 있기 때문에 휴대전화기는 충전이 끝나면 플러그를 뽑거나 멀티탭의 전원스위치를 꺼야 한다. 대부분 휴대전화 충 전기는 충전에 필요한 시간이 약 1 2시간 이하인데도 24 시간 콘센트에 꼽혀있어 약 22 23시간 이상 대기전 력을 낭비하고 절연이 파괴될 경우 전기화재를 유발할 가능성도 있다. 어떤 가정에서 가족원 3 명이 핸드폰충 전기를 1 개월간 방치할 경우, 소비전력 $(2.52 \mathrm{kWh})$ 을 이 산화탄소 배출량으로 환산하면 약 $1 \mathrm{~kg}$ 이 되기 때문에 환경적인 측면에서도 문제가 크다고 할 수 있다.

데스크 탑과 노트북의 부하에 따른 소비전력 변화를 $<$ Table 6>과 <Table 7>에 나타내었다. 이 표에서 확 인할 수 있듯이 컴퓨터에 단순히 USB를 꽂아두는 것 만으로도 전력손실이 부하의 크기만큼 많이 증가하였 다. 따라서 사용하지 않는 컴퓨터는 USB나 배터리 등 과 같은 주변기기를 반드시 제거할 필요성이 있다.

$<$ Table 6> Power consumption by changing the load on the desktop(integrated)

\begin{tabular}{|c|c|c|c|c|c|c|c|}
\hline Load & $\begin{array}{c}\text { USB } \\
\text { PC }\end{array}$ & $\begin{array}{c}\text { USB } \\
\text { unsed }\end{array}$ & $\begin{array}{c}\text { USB } \\
\text { GGB }\end{array}$ & $\begin{array}{c}\text { USB } \\
\text { 8GB }\end{array}$ & $\begin{array}{c}\text { USB } \\
300 G B\end{array}$ & PDA & Printer \\
\hline Desktop & $34.7 \mathrm{~W}$ & 36 & 36.3 & 36.6 & 37.2 & 36.0 & 36.14 \\
\hline $\begin{array}{c}\text { Increase } \\
\text { d loss }\end{array}$ & - & 1.3 & 1.6 & 1.9 & 2.5 & 1.3 & 1.44 \\
\hline
\end{tabular}


$<$ Table $7>$ According to whether or not equipped with a laptop computer battery power consumption changes

\begin{tabular}{|c|c|c|c|}
\hline Laptop & $\begin{array}{c}\text { Removing } \\
\text { the Battery }\end{array}$ & $\begin{array}{c}\text { When charging } \\
\text { the battery } \\
\text { after discharge }\end{array}$ & $\begin{array}{c}\text { Increased } \\
\text { loss }\end{array}$ \\
\hline A Corp. & $17.79[\mathrm{~W}]$ & $59.77[\mathrm{~W}]$ & $41.98[\mathrm{~W}]$ \\
\hline B Corp. & $16.05[\mathrm{~W}]$ & $55.21[\mathrm{~W}]$ & $39.16[\mathrm{~W}]$ \\
\hline
\end{tabular}

한 사업장을 대상으로 사무실에 설치된 $\mathrm{OA}$ 기기별(18 개 종류 총 62점) 대기전력실태 조사 결과, $\mathrm{OA}$ 기기의 평균대기전력은 $6.75[\mathrm{~W}]$ 로 나타났으며, 측정대상 사무 실의 전체 대기전력 합계는 1 시간당 평균 $199.8[\mathrm{~W}]$ 였 다. $\mathrm{OA}$ 기기의 대기전력 측정결과가 제품별로 차이를 보이는 원인은 전원장치의 저항, 코일과 같은 수동 부 품과 금속 산화막 반도체 전계효과 트랜지스터 및 절 연 게이트 양극성 트랜지스터 등 파워스위치, 집적회로 (IC) 사용개수에 따라 대기전력 발생량에서 차이가 난 것으로 분석되었다.

\section{5 대기전력 절전방법제안}

\subsection{1 저가형 절전방법}

하루 작동시간이 1 2시간 이내로 사용하는 $\mathrm{OA}$ 기기 의 경우에도 콘센트에 접속되어 있을 때는 실제로 사 용하는 시간을 제외한 나머지 시간(약 22 23시간) 동 안 계속해서 대기전력을 낭비하고 있다. 따라서 사무실 에서 적은 예산을 투자하여 효율적으로 절전하기 위해 서는 사용자가 손쉽게 대기전력을 차단하거나 절전할 수 있도록 눈에 보이는 절전방법을 사용한다. 실천방안 으로 개인용 $\mathrm{PC}$ 를 비롯하여 공용 $\mathrm{OA}$ 기기의 전원스위 치를 눈에 보이지 않고 손이 닿지 않는 책상 밑이나 캐비닛의 이면 등 후미진 곳에 설치하는 것보다 사용 자의 눈에 쉽게 보이는 책상 위나 옆에 설치하여 사용 이 끝나면 사용자가 가볍게 손을 뺃어 쉽게 전원스위 치를 터치(touch)하여 끌 수 있는 환경을 만들어 대기 전력을 차단하여 절전을 실천해야 한다.

공용으로 사용하는 복사기나 프린터 등 $\mathrm{OA}$ 기기의 전원차단용 멀티탭 스위치는 $1.2 \mathrm{~m}$ 이상의 높이에 설 치하여 사용자나 관리자가 편리한 자세로 전원을 차단 할 수 있는 환경을 조성하여 절전을 손쉽게 실행한다.

개인용 $\mathrm{PC}$ 에 연결하여 사용하는 USB 등 대용량저 장장치는 용량에 따라 전력 소비량이 증가하므로 사용 후에는 $\mathrm{PC}$ 에서 분리하고 노트북을 사무실에서 워드용 으로 사용할 경우에는 배터리를 분리한 후에 이용하면 배터리충전에 관련된 회로를 정지시켜 입력소비전력을
최소한으로 사용할 수 있으므로 전기에너지를 절감할 수 있다.

\subsection{2 중저가형 절전방법}

공용으로 사용하는 $\mathrm{PC}$ 나 $\mathrm{TV}$ 등은 센서나 타이머 또 는 대기전력 자동차단 콘센트 등을 설치하여 컴퓨터를 일정시간 사용하지 않거나 TV를 시청하는 사람이 없 을 때에는 자동으로 인식하여 주변기기들을 연동으로 제어하여 전원을 차단함으로써 절전 한다. 예컨대 프린 터가 연결된 $\mathrm{PC}$ 의 경우, 대기전력의 소모를 최소화하 기 위해서는 대기전력 자동차단 콘센트 1 번 수구에 $\mathrm{PC}$ 본체를 연결하고 2 번 5 번 수구에 $\mathrm{PC}$ 관련 모니터, 프 린터, 스피커 등 기기를 연결하면 1 번 수구에서 사용여 부를 감지하여 일정시간 사용하지 않을 때 2번 5 번 수구를 자동으로 $\mathrm{OFF}$ 하여 대기전력을 차단하여 절전 할 수 있는 대기전력 자동차단 콘센트 등을 사용하는 것이다.

회의실, 휴게실, 문서고, 창고 및 화장실 등에는 카운 터 센서 스위치를 설치하여 출입하는 사람이 없으면 자동으로 전원을 차단하고 사람이 들어오면 자동으로 점등하도록 하면 절전효과가 크게 나타난다. 또한 화 장실 조명 카운터 센서 스위치에 비데와 환풍기를 연 계하여 사용자가 들어오면 전원이 $\mathrm{ON}$ 되고 나가면 $\mathrm{OFF}$ 되도록 하고, 사무실과 휴게실 등에 많이 설치된 냉 - 온수기나 자판기에 타이머를 설치하여 근무시간에 만 작동하고 퇴근시간 이후에는 자동으로 전원 차단하 여 절전과 동시에 전기화재도 예방할 수 있다.

\subsection{3 고가형 절전방법}

키텍시스템(Keytec System)이란 사무실 등의 출입구 에 설치된 키홀더에 키텍을 꽂으면 실내 전원을 공급 받을 수 있는 시스템이다. 사무실, 창고, 강당 등과 같 이 독립된 구획실 별로 키텍같은 시스템을 설치한 후 퇴근하거나 사용하지 않을 때 키텍을 제거하면 팩스, 냉장고 등 상시전원을 공급해야하는 개소를 제외한 모 든 전원이 차단되는 시스템으로 대기전력 절전에 탁월 하다. 따라서 키텍같은 시스템을 도입하면 대기전력을 줄여 비용을 절감할 수 있을 뿐만 아니라 전원이 완전 히 차단되기 때문에 전기화재를 예방할 수도 있다.

사무실을 신축하거나 리모델링할 경우 각 사무실이 나 독립된 사업장에 친환경 네트워크 기반 전력 차단 장치를 설치하여 대기전력을 최소화해야 한다. 사무실, 회의실, 강당에는 재실감지센서 설치하여 이용하는 사 람의 공간사용여부를 적외선센서 등으로 확인 한 후 사용자가 없을 경우 사용기기의 전원을 차단하면 절전 
이 가능하다. 또한 냉 - 난방 - 공조설비 및 조명기구 등 을 원격으로 조작하거나 프로그램에 의해 작동할 수 있는 시설을 하면 효과적으로 대기전력을 줄일 수 있 다. 그리고 사무용기기가 작동하지 않는 상태에서 일정 시간 지속되면 자동으로 인식하여 절전모드로 변환하 여 대기전력을 절감할 수 있는 절전기능이 있는 제품 을 구입하여 전력소모를 절감한다.

\section{3. 결 론}

본 논문에서는 일반 사무실에서 사무용기기의 사용 환경과 $\mathrm{OA}$ 기기별 대기전력 발생패턴에 대해 실측하고 대기전력을 차단하거나 전력손실을 최소화할 수 있는 절전기법을 다음과 같이 제안하였다.

1. 피쳐폰이나 스마트폰을 충전하기 위해 직류전원장 치를 콘센트에 꽂아두고 방치할 경우의 $\mathrm{LED}$ 램프 있는 멀티 탭 스위치를 하루 동안 $\mathrm{ON}$ 상태로 방치할 경우에 는 낭비되는 대기전력은 $10.8[\mathrm{Wh}]$ 의 전력이 소모되었다.

2. 개인용 $\mathrm{PC}$ 에 연결하여 사용하는 USB 등은 사용 후에는 $\mathrm{PC}$ 에서 분리하고 스마트폰이나 피쳐폰도 충전 이 완료된 후에는 충전용 직류전원장치의 스위치를 끄거 나 플러그에서 분리하는 등 절전습관을 생활화해야 한다.

3. 냉-온수기나 자판기는 타이머나 센서를 설치하여 퇴근 후 이용하지 않는 시간 자동으로 전원이 차단되 는 방식을 도입하면 절전과 동시에 전기화재도 예방할 수 있다.

4. 사무실, 창고, 강당 등과 같이 독립된 구획실에 키 텍같은 시스템을 도입하면 대기전력을 줄임은 물론 전 기화재도 예방할 수도 있다.

5. 향후 전기제품은 제조단계에서부터 대기전력을 근 본적으로 차단할 수 있는 기술을 도입하고 사용자는 절전을 적극적으로 실행한다면 산업 생산에 활용할 수 있을 뿐만 아니라 전기재해 예방과 함께 이산화탄소 배출감소로 지구온난화 방지에도 일조할 것으로 기대된다.

\section{4. 참 고 문 헌}

[1] M. G. Kim(2011). "Smart Power Savings Consulting" Kidari. pp. 109.

[2] E. Y. Lee and S. H. Joung(2009) "Analysis Result for the Technical Development Reducing Standby Power in Domestic Major Electric Appliances", Korean Home Management Association, Vol. 27, No. 4, pp. 1-20.
[3] Y. R. Kim(2010). "Performance Standby Power 1W Task and Technology Policy" The Korean Institute of Electrical Engineers, Vol.59, No.12, pp.35-40.

[4] M G. Kim and D. M Choi(2011). "Analysis of standby power monitoring of $\mathrm{OA}$ at intelligent building" The Korean Institute of Electrical Engineers, Vol.1, pp.29-30.

\section{저 자 소 개}

김 만 건

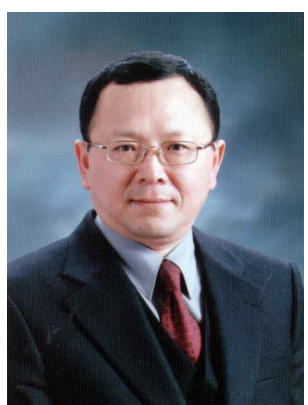

조선대학교에서 학사, 가천대 학교 에서 석사를 취득하였고, 한국전기안전공사에서 직원, 과 장, 부장, 지사장 등을 역임하였 다. 현재는 에너지플러스화재연 구소 대표로 관심분야는 화재조 사(감식 및 감정), 스마트 절전, 전기안전 및 에너지절약과 강연 등이다.

주소: 서울시 서초구 양재2동 394-7 신일방재 3층 에너 지플러스화재연구소 대표

최 돈 묵

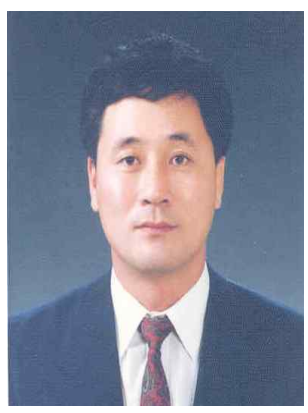

충남대학교에서 학사, 석사, 박사 를 취득하였고 일본 동경공업대 학과 미국버지니아대학에서 연구 객원 교수로 연구 및 교육활동을 하였다. 현재는 가천대학교 소방 방재공학과에서 교수로 재직중 이다. 관심분야는 화재조사(감식 및 감정), 위험물 안전관리 및 소화약제의 소화성능 등이다.

주소: 경기도 성남시 수정구 복정동 산65번지 가천대학 교 공과대학 소방방재공학과 